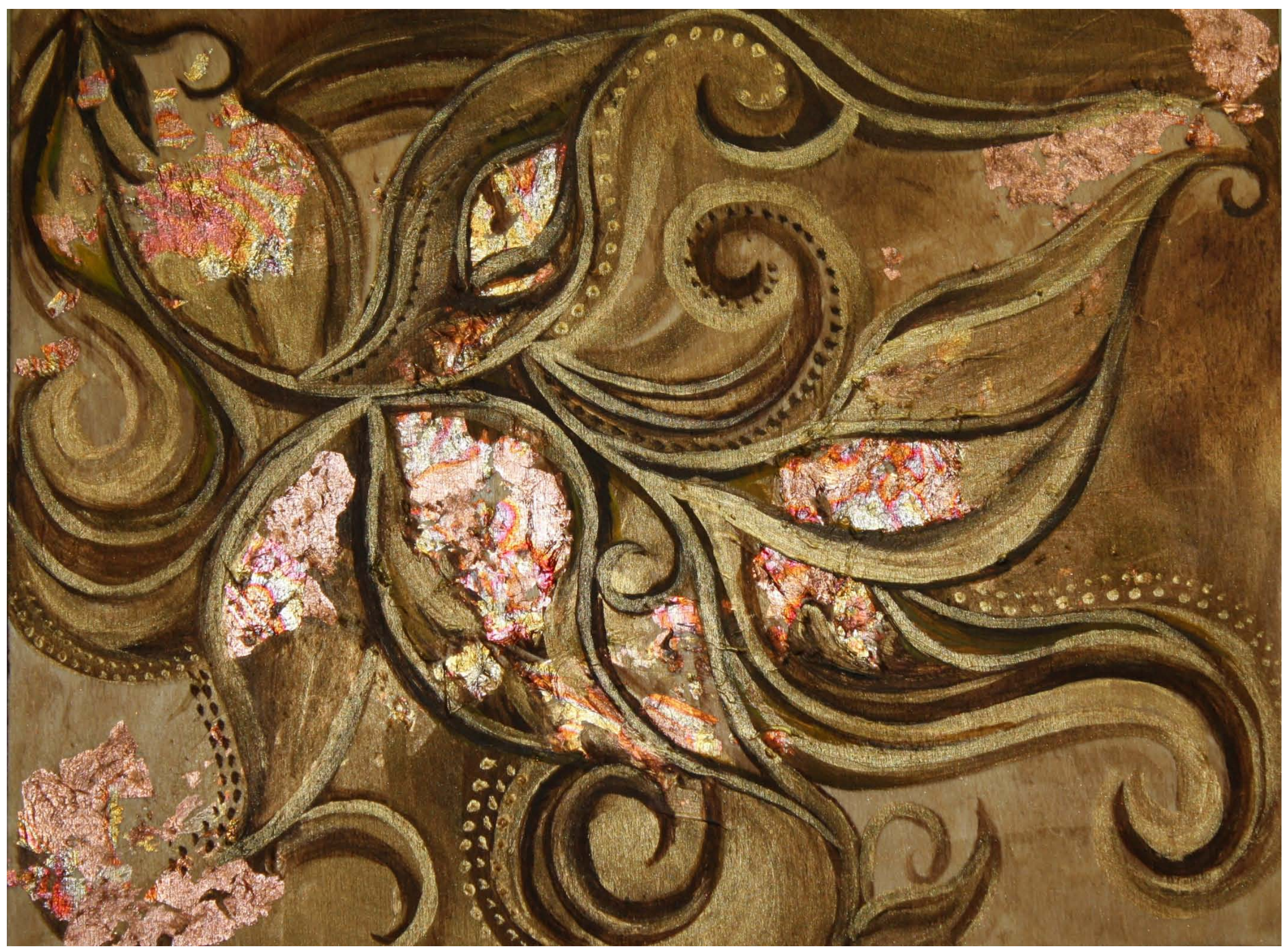

\title{
"Hybrid 2"
}

\section{Ashti-Leah Mindy Rampersad}

My work within the last five and half years has been influenced by my experience growing up in both Trinidad and Canada. My move to Canada has always made me think about what was left behind and the new world I stepped into. Still to this day I am curious about understanding how and why diasporic groups manage to hang on tightly to certain customs from "back home," and how they adapt to a "contemporary" society such as Canada. I started to recognize that some traditions were kept pure, some customs fade due to westernization, and lastly, some become a "hybrid" of both.

An example of a custom that has changed due to western influences would be the art of henna, also known as mehndi. The symbolism of mehndi has been altered due to the media in Canada. Like many customs, the significance and purpose of this sacred tradition has now been taken away by commercialism. Yet, across our borders in places such as India and Trinidad this practice still remains the same; a sacred tradition which has been passed down from generation to generation. 